Jurnal Ilmiah Ibnu Sina, 4(2), Oktober 2019, 452-459

p-ISSN: 2502-647X; e-ISSN: 2503-1902

\title{
EVALUASI YIELD PRODUK TERHADAP FIX COST DAN VARIABLE COST PADA CAIRAN INFUS RINGER LACTATE
}

\author{
Adi Suroso $^{1 *}$, Amelia Lorensia ${ }^{2}$, Abdul Rahem $^{3}$ \\ ${ }^{1}$ Mahasiswa Pascasarjana Ilmu Farmasi, Fakultas Farmasi Universitas Surabaya \\ ${ }^{2}$ Departemen Farmasi Klinis-Komunitas, Fakultas Farmasi, Universitas Surabaya, \\ ${ }^{3}$ Departemen Farmasi Komunitas, Fakultas Farmasi Universitas Airlangga \\ *Email: firstsuroso@gmail.com
}

Artikel diterima: 31 Agustus 2019; Disetujui: 29 Oktober 2019

\begin{abstract}
ABSTRAK
Kebutuhan obat yang bermutu dapat berpengaruh terhadap harga obat, karena dalam proses pembuatannya harus memenuhi persyaratan seperti yang tertuang dalam CPOB. Di sisi lain, harga dari perhitungan sebelum (HPP standar) dan sesudah produksi (HPP varian) dapat berbeda disebabkan oleh adanya perubahan nilai factory over head (fixed cost dan variable cost). Untuk itu diperlukan analisis harga pokok sebelum dan sesudah produksi. Penelitian ini bertujuan menganalisis perbedaan HPP varian produk cairan infus ringer lactate terhadap HPP standar.

Nilai HPP varian dihitung berdasar yield dari 30 batch. Analisis deskriptif dilakukan untuk (1) Nilai (\%) komponen HPP standard (2) Selisih nilai (\%) variabel cost dan fixed cost HPP varian terhadap nilai HPP standard (3) Nilai (\%) HPP varian terhadap HPP standard.

Hasil menunjukkan (1) Komponen HPP standard terdiri atas bahan baku $(6,70 \%)$, bahan kemas $(49,58 \%)$, factory over head dengan variabel cost $(25,80 \%)$ dan Fixed cost (18,00\%); (2) Rata-rata yield 30 batch 94,947 \% diperoleh selisih variabel cost HPP varian - HPP standard 4,422\% dan selisih fixed cost HPP varian - HPP standard 3,958 \% (3) Selisih HPP varian terhadap standard 4,201\%. Yield produk berpengaruh pada variabel cost dan fixed cost HPP varian, menyebabkan gap terhadap HPP standard, untuk itu dipertimbangkan dalam penetapan HPP standard
\end{abstract}

Kata kunci: efektivitas biaya; produksi cairan infus; evaluasi biaya varians

\section{ABSTRACT}

The need for quality drugs can affect the price of drugs, because there were many requirement in the manufacturing process as stated in the GMP standard. On the other hand, the price of the COGS (before production) standard and COGS varian (after production) can be different due to changes in the values of factory over head (fixed cost and variable cost). So that it requires an analysis of COGS standard and variant. This study aims to analyze the differences in the COGS variant of Ringer Lactate infusion products to COGS standard. 
Jurnal Ilmiah Ibnu Sina, 4(2), Oktober 2019, 452-459

p-ISSN: 2502-647X; e-ISSN: 2503-1902

COGS variant value was calculated based on the yield of 30 batches. Descriptive analysis was performed for (1) Value (\%) of COGS standard (2) Differences in value of variable cost and fixed cost of COGS variant to COGS standard, (3) COGS standard and variant.

The results showed (1) COGS standard consist of raw materials (6.70\%), packaging materials (49.58\%), factory over head with variable costs $(25.80 \%)$ and Fixed costs (18.00\%); (2) The average yield of 30 batches was $94.947 \%$ and this causes in differences in variable cost of COGS variant - standard $4.422 \%$ and the differences in fixed cost of COGS variant-COGS standard 3,958\% (3) There was $4,201 \%$ differences in COGS variant to standard. Product yield influences the value of variable cost and fixed cost of COGS variants, causing a gap to the COGS standard. So that this gap should considered in setting the COGS standard.

Keywords: cost effectiveness, infusion fluid production, evaluation of variant cost

\section{PENDAHULUAN}

Kebutuhan obat yang bermutu akan berpengaruh terhadap harga obat, karena tahapan di dalam proses pembuatannya harus memenuhi kaidah-kaidah seperti yang tertuang dalam CPOB. Di sisi lain, konsumen mengharapkan harga obat yang dapat terjangkau namun tetap amandan bermutu (BPOM, 2012). Dalam pelaksanaannya bahwa untuk memproduksi dengan persyaratan CPOB yang sangat ketat diperlukan biaya yang sangat besar sehingga diperlukan perhitungan besar biaya yang harus ditanggung oleh industri farmasi dengan mempertimbangkan harga obat yang dihasilkan dapat dijangkau oleh pasien juga mempertimbangkan

bahwa pemerintah/Departemen Kesehatan sudah menentukan harga obat tertinggi yang diperbolehkan beredar di Indonesia (harga eceran tertinggi), maka dari itu perhitungan biaya produksi sangat penting untuk evaluasi besarnya yield (output) produk terhadap fix cost dan variable cost untuk meminimalkan perbedaan (GAP) pada Harga Pokok Produksi standard dan Harga Pokok Produksi varian. Pada penelitian ini dipilih cairan infus dasar karena sesuai dengan data bahwa kebutuhan dan ketersedian belum sesuai terutama pada cairan infus Ringer Lactate (Srikant dkk, 2018; Wulandari dkk, 2016; Fabozzi dkk, 2008). 
Jurnal Ilmiah Ibnu Sina, 4(2), Oktober 2019, 452-459

p-ISSN: 2502-647X; e-ISSN: 2503-1902

Berdasarkan data bahwa evaluasi perbedaan (GAP) antara ke kebutuhan infus generic pada tahun dua komponen tersebut yang selanjut 2018 sekitar 175 juta botol sedangkan perusahaan dapat melakukan total hasil produksi sekitar 150 juta botol sehingga beberapa industri perhitungan laba/ rugi terhadap bisnis farmasi di Indonesia ingin mengembangkan kapasitasnya untuk memproduksi cairan infus (Kemenkes, 2010; LKPP, 2016). Kebutuhan cairan dasar infus yang banyak dibutuhkan adalah Ringer Lactate.

Dari latar belakang tersebut maka perlu dikaji biaya produksi cairan infus ringer lactate serta biaya varians setelah produksi, sehingga dari analisa biaya yang timbul dapat dievaluasi yield produk terhadap fix cost dan variabel cost untuk meminimal perbedaan ( GAP) HPP Standard dan HPP varian pada cairan infus Ringer Lactate (Docters dkk, 2012; Mulyadi, 2014; Halim, 2010; Ehrlenspiel dkk, 2007)

HPP Standard perhitungan biaya yang dilakukan industri farmasi sebelum produksi. Sedangkan HPP Varian perhitungan biaya setelah produksi (Sitanggang, 2018; Perpres, 2013; Hongren, 2012). Dari perhitungan tersebut maka dapat di yang dijalankan (Emery dkk, 2007; Heizer \& Render, 2008; Case dkk, 2009; Sundjaja \& Barlian, 2001).

\section{METODE PENELITIAN}

Desain Penelitian

Penelitian ini merupakan penelitian analisis deskriptif yang mendiskripsikan dan menghitung komponen harga produksi suatu produk pada saat awal sebelum produksi melalui analisa biaya standard (HPP Standard) dan setelah produksi melalui analisa biaya varians (HPP varians) sebanyak 30 batch pada periode January - Juni 2018 , selanjutnya dilakukan evaluasi yield produk terhadap fix cost dan variable cost untuk meminimalkan perbedaan (GAP) HPP standard dan HPP varian.

\section{Variabel Penelitian}

Variabel bebas dalam penelitian ini adalah harga komponen yang mempengaruhi HPP standard maupun HPP varian yaitu direct labor, utilities, supplies, fuel, dan yield., sedangkan 
Jurnal Ilmiah Ibnu Sina, 4(2), Oktober 2019, 452-459

p-ISSN: 2502-647X; e-ISSN: 2503-1902

variabel terikat meliputi HPP standard dan HPP varian.

\section{HPP Standard}

HPP standard adalah harga untuk produk yang dihitung sebelum produksi termasuk penetapan yield dari produk infus Ringer Lactate

\section{HPP Varians}

HPP variant adalah harga riel termasuk yield yang timbul dari produk infus Ringer Lactate

\section{Populasi dan Sampel}

Populasi pada penelitian ini adalah harga produk infus Ringer Lactate pada periode Januari - Juni 2018

\section{Metode Pengambilan Sampel}

Data diambil sebanyak 30 batch pada periode Januari 2018 - Juni 2018

\section{Analisa Data}

Analisa data dalam penelitian ini menggunakan deskriptip analisis

a. Menghitung \% komponen yang mempengaruhi Harga Pokok Porduksi.

b. Mengitung $\%$ selisih fix cost dan variable cost pada HPP standard dan HPP varian c. Menghitung \% selisih pada HPP standard dan HPP varain terhadap yield dari 30 batch.

\section{HASIL DAN PEMBAHASAN}

Komponen HPP Standar Produk

RL dalam \% terhadap Nilai Total HPP Standard

Dari hasil observasi dan analisis komponen HPP standard untuk produk cairan RL diperoleh hasil sebagaimana ditunjukkan pada tabel 1 dimana :
a. Bahan aktif
: $6,70 \%$
b. Bahan kemasa
: 49,50\%
c. Factory Over Head : 43,80 \% terdiri :
- Variabel cost : 25,80\%
- Fixed cost 18,00\%

Dari komponen HPP standard produk ringer laktat tersebut untuk $\%$ dari bahan aktif dan bahan kemasan tidak mengalami perubahan pada saat produksi dengan besaran batch sebesar 6000 liter dan asumsi 1 batch hasil produksi sebesar 11240 botol $(500 \mathrm{ml})$ namun pada komponen $\mathrm{FOH}$ yang terdiri dari variabel cost dan fix cost dipengaruhi adanya yield (hasil produk jadi) pada proses produksi, sehingga pada step berikutnya 
Jurnal Ilmiah Ibnu Sina, 4(2), Oktober 2019, 452-459

p-ISSN: 2502-647X; e-ISSN: 2503-1902

dilakukan perhitungan selisih nilai variable cost dan fixed cost HPP varian berdasarkan yiled dari 30 batch terhadap nilai HPP standard.

Tabel 1. Komponen HPP standar produk RL dinyatakan dalam \% terhadap nilai total HPP standar

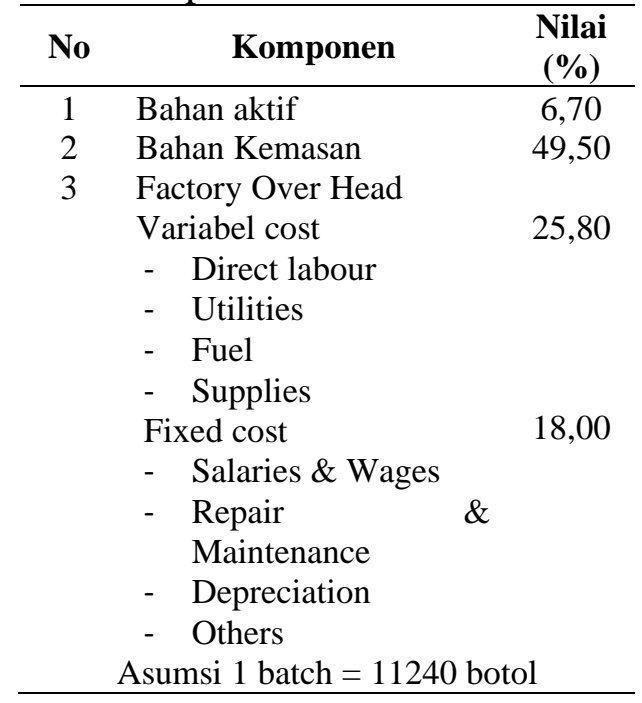

Selisih Nilai Variable Cost dan Fixed Cost HPP Varian berdasarkan Yield dari 30 Batch terhadap Nilai HPP

\section{Standar}

Hasil perhitungan Selisih nilai variable cost dan fix cost HPP varian berdasarkan yield dari 30 batch terhadap nilai HPP standard diperoleh hasil sebagaimana ditunjukkan pada tabel 2 dimana

a. Selisih nilai variable cost pada HPP varian dari 30 batch dengan yield : $89,992 \%-99,902 \%$ adalah
$4,415 \%-4,429 \%$ terhadap variable cost pada HPP standard.

b. Selisih nilai fixed cost pada HPP varian dari 30 batch dengan yield : 89,992\% - 99,902\% adalah $3,900 \%-4,015 \%$ terhadap fix cost pada HPP standard.

Tabel 2. Selesih nilai variabel cost dan fixed cost HPP varian berdasar yield dari 30 batch terhadap nilai terkait dari HPP standar

\begin{tabular}{|c|c|c|c|}
\hline No Batch & $\begin{array}{c}\text { Yield } \\
\text { batch } \\
\text { ke } \\
(\%)\end{array}$ & $\begin{array}{c}\text { Beda } \\
\text { Variabel } \\
\text { cost } \\
\text { HPP } \\
\text { varian - } \\
\text { HPP } \\
\text { standard } \\
(\%)\end{array}$ & $\begin{array}{c}\text { Beda } \\
\text { Fixed } \\
\text { cost } \\
\text { HPP } \\
\text { varian - } \\
\text { HPP } \\
\text { standard } \\
(\%)\end{array}$ \\
\hline Minimum & 89,992 & 4,415 & 3,900 \\
\hline Maximum & 99,902 & 4,429 & 4,015 \\
\hline
\end{tabular}

Selisih nilai variable cost dan fixed cost pada HPP varian terhadap HPP standard disebabkan adanya yiled (hasil produk jadi) dari 30 batch terhadap yield yang ditetapkan pada HPP standard hasilnya berbeda sehingga berpengaruh terhadap vaiabel dan fixed cost.

Selisih nilai HPP Varian berdasarkan Yield dari 30 Batch terhadap Nilai HPP standard

Dari hasil perhitungan selesih nilai HPP varian berdasarkan yield 
Jurnal Ilmiah Ibnu Sina, 4(2), Oktober 2019, 452-459

p-ISSN: 2502-647X; e-ISSN: 2503-1902

dari 30 batch terhadap nilai HPP standard diperoleh hasil sebagaimana ditunjukkan pada tabel 3 dimana: Selisih yield pada HPP varian dibandingkan dengan standard dengan rata-rata sebesar 3,75\% maka selisih nilai HPP varian dibandingkan dengan standard rata-rata sebesar 4,201\%. Selisih yield dari HPP varian dibandingkan HPP standard memberikan dampak pada selisih nilai HPP , hal ini disebabkan dengan yield (hasil produk jadi) jauh lebih rendah dari pada standard yang ditetapkan sehingga berpengeruh pada $\mathrm{FOH}$ (Faktory Over Head) karena yield rendah tetapi $\mathrm{FOH}$ tetap sehingga beban untuk FOH jadi lebih besar

Untuk meminimalkan terjadi GAP (perbedaan) antara HPP standard dengan HPP varian maka perlu dikaji saat menetapkan HPP standard anatara lain : kinerja mesin, standard operating prosedur terhadap mesin,personil yang menjalankan mesin serta personil bagian quality control sehingga dalam menetapkan HPP standard lebih mendekati riel saat produksi. Dalam penelitian sebelumnya dijelaskan bahwa penetapan Harga Pokok
Produksi standard sngat berpengaruh terhadap efektifitas dalam menghitung laba/rugi perusahaan.

Tabel 3. Selisih nilai HPP varian berdasar yield 30 batch terhadap HPP standar (\%)

\begin{tabular}{ccc}
\hline No. Batch & $\begin{array}{c}\text { Selisih } \\
\text { Yield } \\
\text { varian- } \\
\text { standard } \\
(\boldsymbol{\%})\end{array}$ & $\begin{array}{c}\text { Selisih } \\
\text { Nilai HPP } \\
\text { varian - } \\
\text { HPP } \\
\text { standar } \\
(\boldsymbol{\%})\end{array}$ \\
\hline Minimum & 0,10 & 2,500 \\
Maximum & 10,01 & 7,337 \\
Rata-rata & 3,75 & 4.201 \\
\hline
\end{tabular}

\section{KESIMPULAN}

Dari hasil evaluasi komponen yang mempengaruhi perhitungan HPP standard, HPP varian untuk produk infus cairan dasar ringer lactate maka dapat disimpulkan sebagai berikut :

1. Komponen HPP standard produk RL dalam \% terhadap nilai total HPP standard adalah bahan baku $6,70 \%$; bahan kemasan 49,50\% dan factory over head $(\mathrm{FOH})$ $43,80 \%$ ( variable cost $25,80 \%$ dan fixed cost $18,00 \%$ ).

2. Selisih nilai variable cost dan fixed cost HPP varian berdasarkan yield dari 30 batch terhadap nilai HPP standard adalah : 
Jurnal Ilmiah Ibnu Sina, 4(2), Oktober 2019, 452-459

p-ISSN: 2502-647X; e-ISSN: 2503-1902

a. Selisih nilai variable cost pada HPP varian dengan yield : 89,992\% - 99,902\% adalah 4,415 \% - 4,429\% terhadap variable cost pada HPP standard

b. Selisih nilai fixed cost pada HPP varian dengan yield : $89,992 \%-99,902 \%$ adalah $3,900 \%-4,015 \%$ terhadap fix cost pada HPP standard

3. Selisih nilai HPP varian berdasarkan yield dari 30 batch terhadap nilai HPP standard adalah Selisih yield pada HPP Ivarian dibandingkan dengan standard dengan rata-rata sebesar $3,75 \%$ maka selisih nilai HPP varian dibandingkan dengan standard rata-rata sebesar 4,201 $\%$.

\section{DAFTAR PUSTAKA}

Badan Pengawas Obat dan Makanan. Peraturan Kepala Badan Pengawas Obat dan Makanan Republik Indonesia Nomor HK.03.1.33.12.12.8915 Tahun 2012 tentang Penerapan Pedoman Cara Pembuatan Obat yang Baik. Jakarta: Badan POM; 2012.
Charles T.Hongren, Walter T.Horrison Jr.: Accounting, United Stated, Pearson In ternational Edition: 2012 pp. 954-957.

Douglas R. Emery, John D. Finnerty, John D. Stowe : Corporate Financial Management Third Edition, Pearson International Edition 2007, pp 179-180.

Fabozzi, F.J.D., Pamela, P., Poliment, R.S. The Complete CFO Handbook: From Accounting to Accountability. New Jersey : John Wiley \& Sons; 2008 pp. 120-122

Halim, A. Dasar-Dasar Akuntansi Biaya. (Edisi 4).Yogyakarta 2010: BPFE. (pp. 39).

Jay Heizer, Barry Render : Operations Management Ninth Edition, Pearson International Edition 2008, pp 302-305.

Karl E. Case, Ray C. Fair, Sharon M.Oster : Principles of Economics Ninth Edition, Pearson International Edition 2009, pp $253-255$.

Kementrian Kesehatan. Peraturan Menteri kesehatan RI NOMOR 1799/MENKES/PER/XII/2010 tentang Industri Farmasi; 2010

Mulyadi. Biaya. (Edisi 5). Yogyakarta : Sekolah Tinggi Ilmu Manajemen YKPN.2014 (pp. 14).

Peraturan Kepala Lembaga Kebijakan Pengadaan Barang/Jasa Pemerintah (LKPP) nomer 6 tahun 2016 Tentang Katalog 
Jurnal Ilmiah Ibnu Sina, 4(2), Oktober 2019, 452-459

p-ISSN: 2502-647X; e-ISSN: 2503-1902

Elektronik dan E-Purchasing; 2016.

Peraturan Presiden RI No. : 111 tahun 2013 pasal 6 bahwa Kepesertaan Jaminan Kesehatan bersufat wajib dan mencakup seluruh penduduk Indonesia, 2013.

Rob Docters, John G. Hanson, Cecelia Nguyen and Michael Barzelay: The death of List price and the new market reality Contextual Pricing; 2012 pp. 76-78.

Sitanggang, M. L. Peran Katalog Elektronik Obat \& Alata kesehatan dalam Penyelenggaraan JKN. Seminar Peran Katalog Elektronik Obat
\& Alat Kesehatan dalam Penyelenggaraan JKN. Gresik, 1 September 2018.

Srikant, D. M., \& Mandav, R. V. Horngen's Cost Accountig A Manegerial Emphasis. United State: Pearson; 2018.pp 24-25.

Sundjaja dan Barlian . Laporan Keuangan maupun aktivitas perusahaan. 2001 : p 47.

Wulandari, F., \& Atmoko, A. D. Analisis Varians Biaya Produksi Dengan Perhitungan Biaya Standar Sebagai Pengendalian Biaya Produksi. Jurnal Ilmiah Akuntansi, 3(1) 2016, pp. 11-33. 


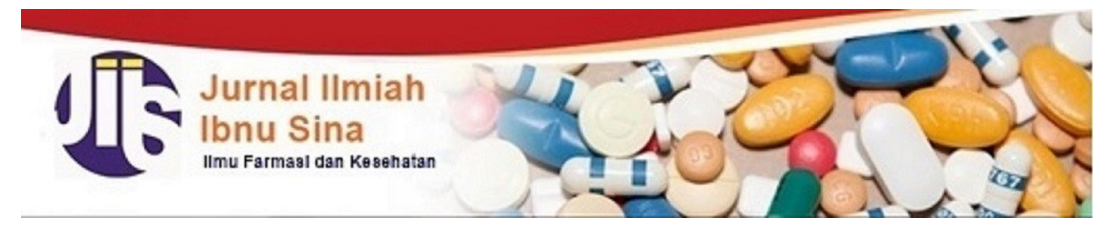

Terkini navigation.archives Pengumuman Tentang Kami

Search

\section{Home / Dewan Editor}

\section{REVIEWER}

Prof. Dr. Suwidjiyo Pramono, DEA., Apt (Universitas Gadjah Mada)

Prof. Dr. Zullies Ikawati, Apt (Universitas Gadjah Mada)

Prof. Agung Endro Nugroho, M.Si., Ph.D., Apt (Universitas Gadjah Mada)

Prof. Abdul Rohman, M.Si., Ph.D., Apt (Universitas Gadjah Mada)

Dr. Brahmaputra Marjadi, MPH., Ph.D. (University of New South Wales)

Dr. Dyah Aryani Perwitasari, M.Si., Ph.D., Apt (Universitas Ahmad Dahlan)

Dr. rer. nat. Endang Darmawan, Apt (Universitas Ahmad Dahlan)

\section{EDITOR}

Siska Musiam, S.Si., M.Si. (Akademi Farmasi ISFI Banjarmasin)

Riza Alfian, S.Farm., M.Sc., Apt (Akademi Farmasi ISFI Banjarmasin)

Mochammad Maulidie Alfiannor Saputera, M.Farm., Apt (Akademi Farmasi ISFI Banjarmasin)

Dwi Rizki Febrianti, M.Farm., Apt (Akademi Farmasi ISFI Banjarmasin)

Rakhmadhan Niah, M.Farm., Apt (Akademi Farmasi ISFI Banjarmasin)

\section{VISITOR}




\section{Visitors}

$\square$ ID 17,162 ZZA 24

医US $1,418 \gg T L 21$

SG $52 \quad \equiv N L 15$

:0: KR 35 IN 11

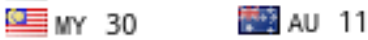

Pageviews: 35,114

173 FLAG counter

View My Stats

\#\#plugins.block.makeSubmission.linkLabel\#\#

JOURNAL TEMPLATE

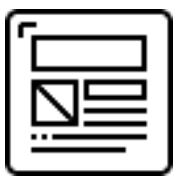

Informasi

For Readers

Untuk Penulis

Untuk Pustakawan

INDEXED BY:

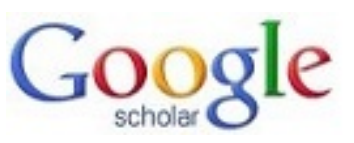

BASE

Onforearch

Cisinta

GARUDA 
p-ISSN: 2502-647X; e-ISSN: 2503-1902

\section{Redaksi Jurnal Ilmiah Ibnu Sina}

Akademi Farmasi ISFI Banjarmasin

Jl. Flamboyan III/7b Kayu Tangi 70123

Banjarmasin Kalimantan Selatan

Telepon: (0511)-3301610, 3300221

Email: jiis@akfar-isfibjm.ac.id

\section{Platform \& workflow by OJS / PKP}




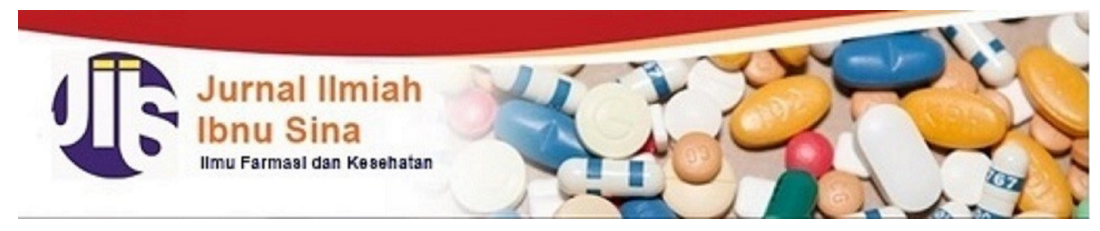

Terkini navigation.archives Pengumuman Tentang Kami

Search

Home / Archives / Vol 4 No 2 (2019)

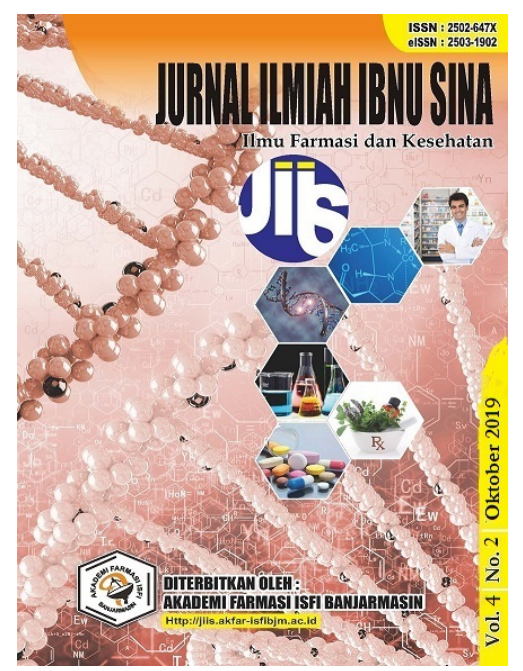

DOI: https://doi.org/10.36387/jiis.v4i2

Diterbitkan: 2019-10-31

\section{Artikel}

STUDI PEMBERIAN INFORMASI TENTANG TEKNIK PENGGUNAAN METERED DOSE INHALER OLEH APOTEKER DAN TENAGA TEKNIS KEFARMASIAN DI APOTEK KECAMATAN MERTOYUDAN, KABUPATEN MAGELANG

Heni Lutfiyati, Tiara Mega Kusuma, Septi Wardani

255-264

因 PDF

KADAR TOTAL ALKALOID, FENOLAT, DAN FLAVONOID DARI EKSTRAK ETIL ASETAT HERBA SURUHAN (Peperomia pellucida [L] Kunth)

Islamudin Ahmad, Maryono Maryono, Abdul Mun'im

265-275 
$ه$ PDF

FORMULASI KRIM EKSTRAK ETANOL BETATAS UNGU (Ipomoea batatas L.)

Sulistianingsih Sulistianingsih, Ravika Ramli, Herlando Sinaga

276-284

因DF

MIKROENKAPSULASI EKSTRAK BUAH BUNI (Antidesma bunius L.) MENGGUNAKAN MALTODEKSTRIN DENGAN METODE SPRAY DRYING

Michrun Nisa, Agustina Ma'tang Parinding, Abdul Halim Umar, Nur Khairi, Astuti Amin, Maulita Indrisari, Wahyu Hendrarti, Andi Nur Aisyah

285-294

且 PDF

POTENSI EKSTRAK KULIT LIMAU BANJAR (Citrus reticulata) DENGAN METODE DPPH SEBAGAI ANTIOKSIDAN

Bela Ghonim Nashucha, Rakhmadhan Niah, Lutfi Anggraini, Winola Exliscia

295-304

因 PDF

UJI VALIDITAS DAN RELIABILITAS KUESIONER KEPATUHAN MGLS (MORISKY, GREEN, LEVINE ADHERENCE SCALE) VERSI BAHASA INDONESIA TERHADAP PASIEN EPILEPSI

Iin Ernawati, Wardah Rahmatul Islamiyah

305-313

因 PDF

IDENTIFIKASI DAN MOLECULAR DOCKING KOMPONEN UTAMA MINYAK KULIT BUAH JERUK NIPIS SEBAGAI AGEN ANTIKANKER

Indah Hairunisa, Normaidah Normaidah, Sylvan Septian Ressandy, Fhirda Azhari

314-322

因 PDF

POTENSI KOMBINASI KAPUR SIRIH DAN DAUN KUMPAI MAHUNG (Eupatorium inulifolium H.B\&K.) SEBAGAI ALTERNATIF SALEP ANTI INFLAMASI ALAMI

Dwi Rizki Febrianti, Siska Musiam

323-330

因 PDF 
Havizur Rahman, Dika Zamri Yanni, Putri Maya Sari, Mia Prajuwita, Intan Lestari

$331-340$

因 PDF

\section{EFEKTIVITAS DAUN RAMANIA ASAL KALIMANTAN SELATAN UNTUK MENURUNKAN KADAR GULA DARAH}

Saftia Aryzki, Yugo Susanto

341-352

因 PDF

\section{OPTIMIZATION OF COPPER NANOPARTICLES SYNTHESIS USING MELINJO SEED EXTRACT}

(Gnetum gnemon L.)

Hilda Aprilia Wisnuwardhani, Arinda Roosma, Yani Lukmayani, Anggi Arumsari, Sukanta Sukanta 353-360

因PDF

ANALISIS BIAYA ANTIBIOTIKA DAN BIAYA PERAWATAN FRAKTUR TULANG DALAM PENETAPAN PEMBIAYAAN KESEHATAN BERDASARKAN INA- CBG'S DI RSUD ULIN BANJARMASIN

Amaliyah Wahyuni, Mochammad Maulidie Alfiannor Saputera

361-369

因 PDF

PENGARUH PEMBERIAN FRAKSI ETIL ASETAT BUAH KASTURI (Mangifera casturi Kosterm) TERHADAP TOKSISITAS AKUT, GAMBARAN MAKROSKOPIS DAN MIKROSKOPIS JANTUNG TIKUS PUTIH JANTAN

Sutomo Sutomo, Gita Meliawati, Arnida Arnida

370-379

且 PDF

UJI AKTIVITAS ANTIBAKTERI FORMULASI SALEP HIDROKARBON DAUN PEPAYA (Carica papaya L.) SEBAGAI SALAH SATU ALTERNATIF OBAT PENYEMBUH LUKA

Erna Prihandiwati, Anna Khumaira Sari

380-390

因 PDF

PROFIL SENYAWA DAN AKTIVITAS ANTIOKSIDAN EKSTRAK DAUN SEPAT (Mitragynaspeciosa) DAN DAUN DADANGKAK (Hydrolea spinosa L.)

Rakhmadhan Niah, Eka Kumalasari

391-399

㘣 PDF 
PENAPISAN VIRTUAL BERBASIS STRUKTUR DARI DATABASE BAHAN ALAM ZINC SEBAGAI INHIBITOR BRUTON TYROSINE KINASE

Fauzan Zein Mutaqqin, Wayan Ayu Puje Astuti, La Ode Aman, Ellin Febrina, Aiyi Asnawi 400-409

因 PDF

EVALUASI TINGKAT KEPATUHAN MINUM OBAT HIPERTENSI PADA PASIEN PROGRAM RUJUK BALIK DI APOTEK MITRA BANJARMASIN

Novia Ariani, Noverda Ayuchecaria

410-419

圆 PDF

PROFIL RENCANA KEBUTUHAN OBAT DI DINAS KESEHATAN PADA DAERAH TERTINGGAL, PERBATASAN DAN KEPULAUAN (STUDI DI KABUPATEN BELU NUSA TENGGARA TIMUR)

Eva Taulabi, Wahyu Utami, Abdul Rahem

420-431

因 PDF

SINTESIS NANOKITOSAN DARI LIMBAH CANGKANG HALILING (Filopaludina javanica) KALIMANTAN SELATAN

Siska Musiam, Noor Aisyah

432-439

因 PDF

PENINGKATAN PRODUKTIVITAS LIMBAH PERTANIAN DAUN BAWANG DAYAK (Eleutherine Palmifolia L. Merr ) SEBAGAI ALTERNATIF KRIM ANTI AGING ALAMI

Eka Kumalasari, Erna Prihandiwati

440-451

因 PDF

EVALUASI YIELD PRODUK TERHADAP FIX COST DAN VARIABLE COST PADA CAIRAN INFUS RINGER LACTATE

Adi Suroso, Amelia Lorensia, Abdul Rahem

452-459

因 PDF

VISITOR 


\section{Visitors}

$\square$ ID 17,162 ZA 24

㕓 US 1,418 $\gg$ TL 21

SG $52 \quad \mathrm{NL} 15$

:0: KR 35 IN 11

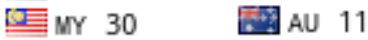

Pageviews: 35,114

is, FLAG counter

View My Stats

\#\#plugins.block.makeSubmission.linkLabel\#\#

JOURNAL TEMPLATE

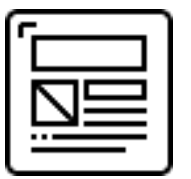

Informasi

For Readers

Untuk Penulis

Untuk Pustakawan

INDEXED BY:

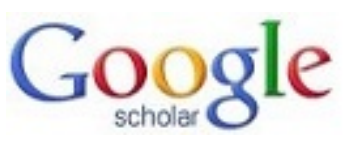

BASE

Onfonearch

C.sinta

\section{GARUDA}


p-ISSN: 2502-647X; e-ISSN: 2503-1902

\section{Redaksi Jurnal Ilmiah Ibnu Sina}

Akademi Farmasi ISFI Banjarmasin

Jl. Flamboyan III/7b Kayu Tangi 70123

Banjarmasin Kalimantan Selatan

Telepon: (0511)-3301610, 3300221

Email: jiis@akfar-isfibjm.ac.id

\section{Platform \& workflow by OJS / PKP}

